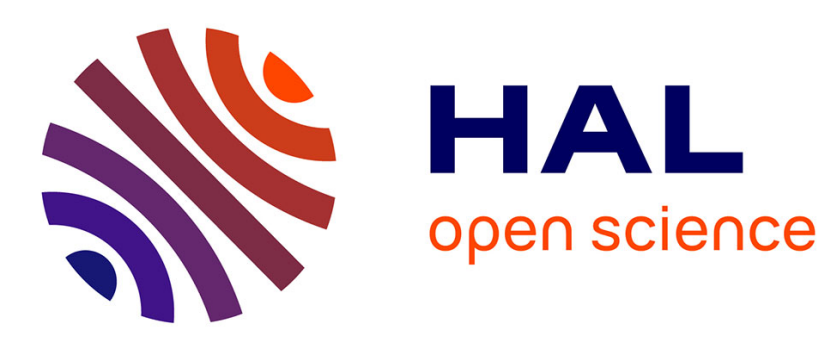

\title{
Use of Gumbel and Weibull functions to model extreme values of diameter distributions in forest stands
}

\author{
J. Javier Gorgoso-Varela, Alberto Rojo-Alboreca
}

\section{To cite this version:}

J. Javier Gorgoso-Varela, Alberto Rojo-Alboreca. Use of Gumbel and Weibull functions to model extreme values of diameter distributions in forest stands. Annals of Forest Science, 2014, 71 (7), pp.741-750. 10.1007/s13595-014-0369-1 . hal-01102773

\section{HAL Id: hal-01102773 \\ https://hal.science/hal-01102773}

Submitted on 13 Jan 2015

HAL is a multi-disciplinary open access archive for the deposit and dissemination of scientific research documents, whether they are published or not. The documents may come from teaching and research institutions in France or abroad, or from public or private research centers.
L'archive ouverte pluridisciplinaire HAL, est destinée au dépôt et à la diffusion de documents scientifiques de niveau recherche, publiés ou non, émanant des établissements d'enseignement et de recherche français ou étrangers, des laboratoires publics ou privés. 


\title{
Use of Gumbel and Weibull functions to model extreme values of diameter distributions in forest stands
}

\author{
J. Javier Gorgoso-Varela • Alberto Rojo-Alboreca
}

Received: 10 January 2014 / Accepted: 27 February 2014 / Published online: 19 March 2014

(C) INRA and Springer-Verlag France 2014

\begin{abstract}
- Context Families of the Gumbel (type I), Fréchet (type II) and Weibull (type III) distributions can be combined in the generalized extreme value (GEV) family of distributions. Maximum and minimum values of diameters in forest stands can be used in forest modelling, mainly to define parameters of the functions used in diameter class models as well as in some practical cases, such as modelling maximum diameters for sawing and processing purposes.

- Aims The purpose of this study was to examine and compare two extreme value distribution functions (the Gumbel and the Weibull functions) in modelling the distribution of the minimum and the maximum values of representative sets of tree diameter samples. Both of these functions were applied to the lower and upper values of the diameter distributions of the main forest species in northwest Spain: Quercus robur L., Betula pubescens Ehrh., Pinus radiata D. Don, Pinus pinaster Ait. and Pinus sylvestris L.

- Methods Parameters of the Gumbel function were estimated using the mode and the moments of the distributions, and parameters of the Weibull function were estimated using the moments method.
\end{abstract}

Handling Editor: Aaron R. Weiskittel

Contribution of the co-authors Co-author provided me data about the species studied

J. J. Gorgoso-Varela $(\bowtie)$

Departamento de Biología de Organismos y Sistemas, Escuela Politécnica de Mieres, Universidad de Oviedo, C/ Gonzalo Gutiérrez Quirós s/n., 33600 Mieres, Asturias, Spain

e-mail: gorgoso@uniovi.es

\section{A. Rojo-Alboreca}

Unidade de Xestión Forestal Sostible (UXFS), Departamento de

Enxeñaría Agroforestal, Escola Politécnica Superior, Campus

Universitario, Universidade de Santiago de Compostela,

27002 Lugo, Galicia, Spain
- Results In general, the Weibull distribution was the most suitable model for describing the maximum diameters. The mode method of the Gumbel yielded the best results for minimum diameters of birch and Monterrey pine. The Gumbel distribution, fitted by either the mode- or momentsbased methods, proved more suitable than the Weibull distribution for describing the minimum diameters in maritime pine and Scots pine stands.

- Conclusion In some cases, better results were obtained with the Gumbel than the Weibull distribution for describing the distribution of extreme diameter values in forest stands in northwest Spain. This is the first example of the application of the Gumbel distribution in forest modelling.

Keywords Cumulative distribution function $\cdot$ Maximum diameter $\cdot$ Minimum diameter $\cdot$ Moments $\cdot$ Mode

\section{Introduction}

In probability theory and statistics, the Gumbel distribution (Gumbel 1954) is used to model the distribution of the maximum or the minimum values of a number of samples of various distributions. For example, in hydrology, the Gumbel probability distribution is used to analyse variables such as monthly and annual maximum values of daily rainfall and river discharge volumes (Ritzema 1994) and also to describe droughts (Burke et al. 2010). It is also used to predict when extreme events such as earthquakes, floods and other natural disasters will occur.

Extreme value theory indicates that the Gumbel distribution will be useful for representing the distribution of maxima if the underlying sample data is of the normal or exponential type. Maximum tree diameters in forest stands probably follow this distribution. However, minimum diameter distributions 
are sometimes truncated because the minimum inventoried diameter considered is $5 \mathrm{~cm}$, which is often the mode value of the extreme value distribution. In such cases, the Weibull distribution, which can be used to describe distributions with a reverse J-shaped curve, may be more suitable than the Gumbel distribution.

The Gumbel distribution is a specific example of the generalized extreme value distribution (also referred to as the Fisher-Tippett distribution). It is also known as the logWeibull distribution and the double exponential distribution which is sometimes also called the Laplace distribution. It is often wrongly called the Gompertz distribution (Willemse and Kaas 2007).

In the present study, the Weibull cumulative distribution function (CDF) was compared with the Gumbel CDF for describing extreme diameter values (maximum and minimum values). Because the Weibull CDF is simple and flexible (Bailey and Dell 1973), it is often used in forestry studies (Maltamo et al. 1995; Kangas and Maltamo 2000; Zhang et al. 2003; Liu et al. 2004). Families of the Gumbel (type I), Fréchet (type II) and Weibull (type III) distributions can be combined in the generalized extreme value (GEV) family of distributions (Persson and Rydén 2010).

Application of the Gumbel CDF or Weibull CDF to forest stands may be useful for describing extreme values of maximum or minimum diameters at different working scales (stand, forest, region). These extreme values are not usually of great interest in most practical cases; for example, timber products are often classified for different industrial uses after felling. However, maximum diameters are important in relation to the choice of harvesting machines used, and harvesting and felling may be limited by the size of machine heads.

The main interest in determining the distribution of these extreme values (maximum and minimum) is for application in forest modelling research. For example, diameter class models are based on probability density functions (PDFs) or CDFs, such as the gamma, Weibull, beta and Johnson's $S_{B}$ functions, which depend on a predetermined location parameter that is usually related to the minimum value of each distribution (Knoebel and Burkhart 1991; Zhang et al. 2003; Parresol 2003; Cao 2004; Fonseca et al. 2009). Knowledge of the distribution of minimum diameters can help in the choice of the most suitable value for the location parameter of these distributions or even in deciding to dispense with this parameter and to use the two-parameter models of the Weibull or gamma functions instead of the threeparameter functions (Maltamo et al. 1995). Furthermore, the maximum diameter of the distributions and the upper limit of the highest diameter class, which depend on the maximum diameter, are usually used as the upper boundary in four-parameter distributions such as the beta function (Zöhrer 1969, 1970; Loetsch et al. 1973; Gorgoso-Varela et al. 2008). This value is also used as a scale parameter, in the Johnson's $S_{B}$ four-parameter distribution (Gorgoso et al. 2012) or in combination with the minimum diameter to calculate the range used as the scale parameter (Schreuder and Hafley 1977; Scolforo et al. 2003). The maximum diameter is also considered as an independent variable in some generalized height-diameter models (Lenhart 1968; Amateis et al. 1995). Readers may also be able to identify new applications.

Birch (Betula pubescens Ehrh.) and pedunculate oak (Quercus robur L.) are two of the most important naturally distributed forest tree species in northwest Spain. B. pubescens, which is considered a fast-growing pioneer species, covers an area of almost 32,000 ha in Galicia and 17,000 ha in the adjoining region of Asturias (MMAMRM Ministerio de Medio Ambiente y Medio Rural y Marino 2011), usually as the dominant species in mixed stands with other hardwoods and conifers. These stands are mainly derived from natural regeneration, frequently on abandoned land, although they are occasionally established as plantations. Q. robur is the dominant tree species of the climax vegetation in many of the native forests in northwest (NW) Spain, and it covers nearly 125,000 ha in pure stands and 250,000 ha in mixed stands in Galicia and 16,000 ha in Asturias, mainly derived from forest regeneration (MMAMRM Ministerio de Medio Ambiente y Medio Rural y Marino 2011).

Maritime pine (Pinus pinaster Ait.), Monterrey pine (Pinus radiata D. Don) and Scots pine (Pinus sylvestris L.) stands are important natural resources in northwest Spain. These species mainly occur in pure stands but sometimes also in mixed stands. Pinus spp. and Eucalyptus globulus Labill. are the most commonly used species in productive stands in this area of Spain. Pure stands of maritime pine cover 217,281 ha in the region of Galicia and 22,523 ha in the adjoining region of Asturias; these stands are mainly derived from natural regeneration, although they are occasionally established as plantations. Exotic Monterrey pine covers 96,177 ha in Galicia and 25,385 ha in Asturias, always in plantations. Scots pine stands cover 32,736 and 7,916 ha in Galicia and Asturias, respectively, also in plantations (MMAMRM Ministerio de Medio Ambiente y Medio Rural y Marino 2011).

The main purpose of this study was to examine and compare the performance of two extreme value distribution functions, the Gumbel and the Weibull CDFs, in modelling the distribution of the minimum and the maximum values of representative sets of tree diameter samples of $Q$. robur, $B$. pubescens, $P$. radiata, $P$. pinaster and $P$. sylvestris in northwest Spain. This is the first example of the application of the Gumbel CDF in forest modelling. 


\section{Materials and methods}

\subsection{Data}

Tree diameter measurements were made in 172 permanent research plots in pedunculate oak ( $Q$. robur) stands, 202 plots in birch (B. pubescens) stands, 325 plots in Monterrey pine $(P$. radiata) stands, 183 plots in maritime pine $(P$. pinaster) stands and 155 in Scots pine (P. sylvestris) stands in NW Spain (in the regions of Galicia and Asturias). In pine stands, the size of the plots ranged from 400 to $1,200 \mathrm{~m}^{2}$, depending on the stand density, in order to achieve a minimum of 30 trees per plot. In birch stands, the size of the plots ranged from 200 to $1,000 \mathrm{~m}^{2}$. In pedunculate oak stands, the size of the plots ranged from 225 to $1,345 \mathrm{~m}^{2}$ to achieve a minimum of 30 trees per plot. Summary statistics including mean, maximum and minimum values and standard deviation of the main stand variables (quadratic mean diameter, number of trees per hectare, basal area and dominant height) are shown in Table 1. The research plots used in the present study were established in stands dominated by the subject tree species (more than $85 \%$ of species standing basal area) and were established to cover a wide variety of combinations of age, number of trees per hectare and site. All trees in each plot were numbered. Two perpendicular diameters at breast height were measured with calipers, to the nearest $0.1 \mathrm{~cm}$, and the arithmetic average was calculated. The empirical data represent left-truncated distributions in some cases, as the smallest diameter measured in the field was $5 \mathrm{~cm}$ (trees smaller than this were not considered). The minimum and the maximum diameters from each distribution were extracted to form the experimental distributions of extreme values by species, used for model parameterization.

The main descriptive statistics of the distributions under study, including the mean; maximum and minimum values; 25th, 50th and 75th percentiles; standard deviation and skewness and kurtosis coefficients are summarized in Table 2.

\subsection{Examined models}

\subsubsection{The generalized extreme value distribution}

Extreme value distributions were first derived by Fisher and Tippett (1928) to describe forms of the frequency distribution of the largest or smallest member of a sample. The GEV distribution has the following CDF for a random variable $x$ :

$F(x, \mu, \sigma, \xi)=\exp \left\{-\left[1+\xi\left(\frac{x-\mu}{\sigma}\right)\right]^{\frac{-1}{\xi}}\right\}$.

For $1+\xi\left(\frac{x-\mu}{\sigma}\right)>0$

where $\mu$ is the location parameter, $\sigma$ is the scale parameter and $\xi$ is the shape parameter. The shape parameter $(\xi)$ governs the tail behaviour of the distribution. The subfamilies defined by $\xi=0, \xi>0$ and $\xi<0$ correspond to the Gumbel (type I), Fréchet (type II) and Weibull (type III) families, respectively,
Table 1 Summary of the main descriptive statistics of stand variables for five tree species in NW Spain $d g$ quadratic mean diameter $(\mathrm{cm})$ $N$ density (trees $\cdot$ ha $^{-1}$ ), $H_{0}$ dominant height (m), $G$ basal area $\left(\mathrm{m}^{2} \cdot \mathrm{ha}^{-1}\right)$

\begin{tabular}{|c|c|c|c|c|c|}
\hline & Variable & Mean & Maximum & Minimum & Standard deviation \\
\hline \multirow[t]{4}{*}{ Quercus robur L. $(N=172)$} & $\mathrm{dg}$ & 21.9 & 40.0 & 8.6 & 6.1 \\
\hline & $N$ & 874 & 3,022 & 302 & 482 \\
\hline & $H_{0}$ & 17.0 & 25.6 & 7.2 & 3.3 \\
\hline & $G$ & 28.3 & 72.9 & 3.4 & 9.2 \\
\hline \multirow[t]{4}{*}{ Betula pubescens Ehrh. $(N=202)$} & $\mathrm{dg}$ & 15.1 & 26.1 & 7.4 & 3.8 \\
\hline & $N$ & 1,691 & 6,000 & 350 & 1,078 \\
\hline & $H_{0}$ & 16.1 & 24.5 & 3.7 & 3.7 \\
\hline & $G$ & 26.7 & 76.4 & 3.3 & 11.1 \\
\hline \multirow[t]{4}{*}{ Pinus pinaster Ait. $(N=183)$} & $\mathrm{dg}$ & 22.2 & 41.5 & 6.8 & 11.9 \\
\hline & $N$ & 1,107 & 3,031 & 363 & 566 \\
\hline & $H_{0}$ & 15.0 & 30.6 & 5.1 & 5.3 \\
\hline & $G$ & 36.1 & 75.7 & 7.1 & 15.0 \\
\hline \multirow[t]{4}{*}{ Pinus radiata D. Don $(N=325)$} & $\mathrm{dg}$ & 21.9 & 48.4 & 5.7 & 9.1 \\
\hline & $N$ & 973 & 4,864 & 200 & 486 \\
\hline & $H_{0}$ & 19.4 & 39.8 & 5.9 & 6.3 \\
\hline & $G$ & 32.7 & 87.1 & 4.9 & 14.5 \\
\hline \multirow[t]{4}{*}{ Pinus sylvestris L. $(N=155)$} & $\mathrm{dg}$ & 17.4 & 27.9 & 7.5 & 4.4 \\
\hline & $N$ & 1,495 & 3,650 & 620 & 471 \\
\hline & $H_{0}$ & 12.1 & 22.6 & 4.0 & 4.3 \\
\hline & $G$ & 34.2 & 74.2 & 4.2 & 14.4 \\
\hline
\end{tabular}


Table 2 Main descriptive statistics of the distributions studied: mean; maximum and minimum values; 25th, 50th and 75th percentiles; standard deviation and skewness and kurtosis coefficients

\begin{tabular}{|c|c|c|c|c|c|c|c|c|c|c|}
\hline & & Mean & Maximum & Minimum & $P_{25}$ & $P_{50}$ & $P_{75}$ & Standard deviation & As & Kur \\
\hline \multirow[t]{2}{*}{ Quercus robur } & $d_{\max }$ & 37.71 & 67.50 & 16.30 & 31.87 & 36.85 & 42.77 & 9.45 & 0.57 & 0.75 \\
\hline & $d_{\min }$ & 8.37 & 25.35 & 5.00 & 5.85 & 7.7 & 9.35 & 3.46 & 1.98 & 5.01 \\
\hline \multirow[t]{2}{*}{ Betula pubescens } & $d_{\max }$ & 25.62 & 42.50 & 11.90 & 20.8 & 24.6 & 30.4 & 6.82 & 0.36 & -0.36 \\
\hline & $d_{\min }$ & 6.60 & 14.00 & 5.00 & 5.15 & 5.75 & 7.37 & 2.03 & 1.53 & 1.59 \\
\hline \multirow[t]{2}{*}{ Pinus pinaster } & $d_{\max }$ & 30.97 & 63.20 & 8.60 & 20.15 & 30 & 39.75 & 12.17 & 0.38 & -0.57 \\
\hline & $d_{\min }$ & 9.38 & 21.70 & 5.00 & 5.4 & 7.42 & 12.52 & 4.51 & 0.95 & -0.16 \\
\hline \multirow[t]{2}{*}{ Pinus radiata } & $d_{\max }$ & 37.29 & 72.90 & 11.10 & 26.2 & 34.4 & 49.3 & 13.57 & 0.38 & -0.88 \\
\hline & $d_{\min }$ & 8.64 & 31.60 & 5.00 & 5.11 & 6.2 & 10.43 & 5.35 & 1.82 & 3.10 \\
\hline \multirow[t]{2}{*}{ Pinus sylvestris } & $d_{\max }$ & 28.00 & 49.20 & 10.80 & 22.67 & 27.6 & 33.22 & 7.01 & 0.23 & -0.02 \\
\hline & $d_{\min }$ & 7.27 & 17.10 & 5.00 & 5.27 & 6.22 & 8.4 & 2.67 & 1.68 & 2.52 \\
\hline
\end{tabular}

$d_{\max }$ maximum diameters, $d_{\min }$ minimum diameters, $P_{25}$ 25th percentile, $P_{50}$ 50th percentile, $P_{75} 75$ th percentile, $A s$ skewness coefficient, $K u r$ kurtosis coefficient

although the reversed Weibull is the model used to link the three distributions in the GEV.

\subsubsection{The Gumbel distribution}

The probability density function (PDF) and the CDF (Gumbel 1954) are formulated for a random variable $x$ as follows:

$$
\begin{aligned}
P D F: f(x, \mu, \beta) & =\frac{1}{\beta} \exp [-(z+\exp (-z))] \\
\text { where } z & =\frac{x-\mu}{\beta} ;-\infty<x<\infty
\end{aligned}
$$

$C D F: F(x ; \mu, \beta)=\exp \left[-\exp \left(-\frac{x-\mu}{\beta}\right)\right] ;-\infty<x<\infty(3)$

where $\mu$ is the mode value (location parameter), $\beta$ is the scale parameter estimated with Eq. 4, and the standard deviation $(\sigma)$ is

$\sigma=\beta \pi / \sqrt{6}$

The function was fitted once using the experimentally determined value of the mode $(\mu)$ and in a second case as a location parameter $\widehat{\mu}$ recovered from the experimental mean $(\bar{d})$ and standard deviation $(\sigma)$ of the distributions. The first and the second moments of the distributions (mean $\bar{d}$ and variance $\sigma^{2}$ ) were applied, by using the following expression:

$\bar{d}=\widehat{\mu}+\beta \gamma$ where $\gamma$ is the Euler-Mascheroni constant:

$$
\gamma=\lim _{n \rightarrow \infty}\left(\sum_{k=1}^{n} \frac{1}{k}-\ln (n)\right)=\int_{1}^{\infty}\left(\frac{1}{\lfloor x\rfloor}-\frac{1}{x}\right) d x \approx 0.577215
$$

\subsubsection{The Weibull distribution}

The three-parameter Weibull CDF is obtained by integrating the Weibull PDF, and it has the following expression for a continuous random variable $x$ :

$P D F: f(x, \mu, \beta, \alpha)=\frac{\alpha}{\beta}\left(\frac{x-\mu}{\beta}\right)^{\alpha-1} \exp \left[-\left(\frac{x-\mu}{\beta}\right)^{\alpha}\right]$

$C D F: F(x ; \mu, \beta, \alpha)=1-\exp \left[-\left(\frac{x-\mu}{\beta}\right)^{\alpha}\right]$

where $\mu$ is the location parameter, $\beta$ is the scale parameter and $\alpha$ is the shape parameter. The scale parameter $\beta$ and shape parameter $\alpha$ of the Weibull distribution were obtained by the method of moments. Location parameter $\mu$ was predetermined as the minimum value in each distribution, and diameter classes of $1 \mathrm{~cm}$ were used in both distributions.

\subsubsection{Fits of the Weibull distribution}

The most commonly used estimation methods for fitting the Weibull distribution are the maximum likelihood estimation, the traditional method of moments, the method of moments incorporating skewness and the percentile method (Zhang et al. 2003). In this study, the traditional method of moments was chosen because the moments of the distribution also were used in the Gumbel CDF approach. 
The method of Moments used by Shifley and Lentz (1985), Nanang (1998), Stankova and Zlatanov (2010) and Gorgoso et al. (2012) is based on the relationship between the parameters of the Weibull function and the first and second moments of the diameter distribution (mean diameter and variance, respectively):

$$
\begin{aligned}
\beta & =\frac{\bar{d}-\mu}{\Gamma\left(1+\frac{1}{\alpha}\right)} \\
\sigma^{2} & =\frac{(\bar{d}-\mu)^{2}}{\Gamma^{2}\left(1+\frac{1}{\alpha}\right)} \cdot\left[\Gamma\left(1+\frac{2}{\alpha}\right)-\Gamma^{2}\left(1+\frac{1}{\alpha}\right)\right]
\end{aligned}
$$

where $\bar{d}$ is the arithmetic mean diameter of the distribution, $\sigma^{2}$ is the variance and $\Gamma(i)$ is the gamma function. Equation 9 was resolved by a bisection iterative procedure (Gerald and Wheatley 1989). Both distributions were fitted using SAS/ STAT $^{\mathrm{TM}}$ software (SAS Institute 2003).

\subsubsection{Practical application}

Information about the scale parameters of the minimum extreme value distributions such as the Gumbel and the Weibull distributions can help researchers to choose the most suitable value of the location parameter in three-parameter or fourparameter PDFs or CDFs commonly used in forest modelling, such as the Weibull, gamma, Johnson's $S_{B}$ and beta distributions. This avoids the need to use complicated and laborious algorithms as used for example by Scolforo et al. (2003) and Gorgoso et al. (2012).

\subsection{Goodness of fits}

We evaluated the consistency of the model and the estimating method by using the Kolmogorov-Smirnov statistic $\left(D_{n}\right)$ for a given cumulative distribution function $F(x): D_{n}=\sup _{x} \mid F_{n}(x)-$ $F_{0}(x) \mid$, where $\sup _{x}$ is the supremum of the set of distances. This value was calculated as follows (Cao 2004):

$D_{n}=\max \left\{\max _{1 \leq i \leq n_{i}}\left[F_{n}\left(x_{i}\right)-F_{0}\left(x_{j}\right)\right], \max _{1 \leq i \leq n_{i}}\left[F_{0}\left(x_{j}\right)-F_{n}\left(x_{i-1}\right)\right]\right\}$

where the cumulative observed frequency $F_{n}\left(x_{i}\right)$ is compared with the cumulative estimated frequency $F_{0}\left(x_{j}\right)$.

We also used the bias, mean absolute error (MAE) and mean square error (MSE) as goodness-of-fit measures; these were expressed as follows:

$\operatorname{Bias}=\frac{\sum_{i=1}^{N}\left(Y_{i}-\widehat{Y}_{i}\right)}{N}$

MAE $=\frac{\sum_{i=1}^{N}\left|Y_{i}-\widehat{Y}_{i}\right|}{N}$

$\mathrm{MSE}=\frac{\sum_{i=1}^{N}\left(Y_{i}-\widehat{Y}_{i}\right)^{2}}{N}$

where $Y_{i}$ is the relative frequency of trees observed value in each diameter class, $\widehat{Y}_{i}$ is the theoretical value predicted by the model and $N$ is the number of data points.

The bias, MAE and MSE values were calculated for the mean relative frequency of trees to determine the goodness of fits. Bias may be less important in the comparison of results because errors with different signs can be compensated.

\section{Results}

Table 3 shows the parameter values of the Gumbel distribution estimated using the mode value $(\mu)$ and the estimated mode $(\widehat{\mu})$ and the three parameters $(\mu, \beta$ and $\alpha)$ of the Weibull distribution.

Table 4 shows the mean values of bias, MAE and MSE of the relative frequencies of trees and the value of the Kolmogorov-Smirnov statistic $\left(D_{n}\right)$ for the fits with both distributions of five tree species in forest stands in NW Spain. The observed and cumulative distributions fitted using the Gumbel and Weibull CDFs to describe extreme values of diameters in five species in northwest Spain are shown in Fig. 1. The mode method was not included in the maximum diameter charts because of the poor results obtained with this approach.

The most suitable order for considering the statistics is probably as follows: the Kolmogorov-Smirnov $\left(D_{n}\right)$ statistic and the MSE, followed by the MAE and finally the bias (because errors with different signs can cancel each other out, thus confounding the overall value). 
Table 3 Parameter values for the Gumbel and the Weibull distributions in the fits to extreme diameter values in forest stands

\begin{tabular}{|c|c|c|c|c|c|}
\hline & Parameters & & $\mu$ & $\hat{\mu}$ & $\beta$ \\
\hline \multirow{10}{*}{$\begin{array}{l}\text { Gumbel } \\
\text { (moments) }\end{array}$} & \multirow[t]{2}{*}{ Quercus robur } & $d_{\max }$ & - & 33.4 & 7.4 \\
\hline & & $d_{\min }$ & - & 6.8 & 2.7 \\
\hline & \multirow[t]{2}{*}{ Betula pubescens } & $d_{\max }$ & - & 22.5 & 5.3 \\
\hline & & $d_{\min }$ & - & 5.7 & 1.6 \\
\hline & \multirow[t]{2}{*}{ Pinus pinaster } & $d_{\max }$ & - & 25.5 & 9.5 \\
\hline & & $d_{\min }$ & - & 7.3 & 3.5 \\
\hline & \multirow[t]{2}{*}{ Pinus radiata } & $d_{\max }$ & - & 31.2 & 10.6 \\
\hline & & $d_{\min }$ & - & 6.2 & 4.2 \\
\hline & \multirow[t]{2}{*}{ Pinus sylvestris } & $d_{\max }$ & - & 24.8 & 5.5 \\
\hline & & $d_{\min }$ & - & 6.1 & 2.1 \\
\hline \multirow{11}{*}{$\begin{array}{l}\text { Gumbel } \\
\text { (mode) }\end{array}$} & \multirow[t]{2}{*}{ Quercus robur } & $d_{\max }$ & 40.7 & - & 7.4 \\
\hline & & $d_{\min }$ & 5.0 & - & 2.7 \\
\hline & \multirow[t]{2}{*}{ Betula pubescens } & $d_{\max }$ & 24.6 & - & 5.3 \\
\hline & & $d_{\min }$ & 5.0 & - & 1.6 \\
\hline & \multirow[t]{2}{*}{ Pinus pinaster } & $d_{\max }$ & 17.4 & - & 9.5 \\
\hline & & $d_{\min }$ & 5.0 & - & 3.5 \\
\hline & \multirow[t]{2}{*}{ Pinus radiata } & $d_{\max }$ & 26.5 & - & 10.6 \\
\hline & & $d_{\min }$ & 5.0 & - & 4.2 \\
\hline & \multirow[t]{2}{*}{ Pinus sylvestris } & $d_{\max }$ & 31.1 & - & 5.5 \\
\hline & & $d_{\min }$ & 5.0 & - & 2.1 \\
\hline & Parameters & & $\mu$ & $\beta$ & $\alpha$ \\
\hline \multirow{10}{*}{$\begin{array}{l}\text { Weibull } \\
\text { (moments) }\end{array}$} & \multirow[t]{2}{*}{ Quercus robur } & $d_{\max }$ & 16.30 & 24.15 & 2.41 \\
\hline & & $d_{\min }$ & 5.00 & 3.34 & 0.98 \\
\hline & \multirow[t]{2}{*}{ Betula pubescens } & $d_{\max }$ & 11.90 & 15.49 & 2.11 \\
\hline & & $d_{\min }$ & 5.00 & 1.40 & 0.79 \\
\hline & \multirow[t]{2}{*}{ Pinus pinaster } & $d_{\max }$ & 8.60 & 25.22 & 1.91 \\
\hline & & $d_{\min }$ & 5.00 & 4.32 & 0.97 \\
\hline & \multirow[t]{2}{*}{ Pinus radiata } & $d_{\max }$ & 11.10 & 29.55 & 2.02 \\
\hline & & $d_{\min }$ & 5.00 & 6.87 & 1.21 \\
\hline & \multirow[t]{2}{*}{ Pinus sylvestris } & $d_{\max }$ & 10.80 & 19.35 & 2.64 \\
\hline & & $d_{\min }$ & 5.00 & 2.10 & 0.85 \\
\hline
\end{tabular}

$d_{\max }$ maximum diameters, $d_{\min }$ minimum diameters

The Weibull distribution was generally the most suitable model for describing the maximum diameters of $B$. pubescens, $P$. pinaster, $P$. radiata and $P$. sylvestris. However, it is a much more complex model than the Gumbel distribution, and iterative procedures must be used in the method of moments fits. The Gumbel distribution fitted by the moments method also yielded good results for maximum diameters (see Fig. 1), although this is a simpler and thus less flexible model.

When the observed mode value was used to fit the Gumbel distribution, the best results were obtained for the minimum diameters of $B$. pubescens and $P$. radiata stands. However, poor results were obtained in the other cases, indicating that this fit is not a viable alternative for modelling maximum diameters. For $Q$. robur stands, the Gumbel and the Weibull distributions fitted by the moments approach yielded equally good results. Finally, the Gumbel distribution fitted by the observed mode method or by the estimated mode method (moments) is more suitable than the Weibull distribution for modelling minimum diameters in $P$. pinaster and $P$. sylvestris stands.

\section{Discussion}

In this study, we tested a new distribution function to model a large number of permanent plots of five tree species, which represent the wide heterogeneity and complexity of forest stands in NW Spain. This is the first evaluation of the Gumbel CDF in the field of forest modelling, although the function is applied in other environmental sciences such as hydrology. We compared moments- and mode-based methods for estimating the Gumbel CDF because the lowest value in many left-truncated distributions is the minimum inventoried diameter $(5 \mathrm{~cm})$, which is the mode of the extreme value distributions. Minimum diameter distributions do not follow a theoretical normal or exponential model, and the Gumbel CDF fitted by the mode yielded the best results for minimum diameters of $B$. pubescens and $P$. radiata stands in which the values of the 25 th and 50th percentiles were the lowest (see Table 2 and Fig. 1d, h). Probability density functions such as Johnson's $S_{B}$ were fitted using the real mode value (Hafley and Buford 1985), although poorer results were obtained than with other methods based on percentiles, moments or maximum likelihood (Zhou and McTague 1996; Zhang et al. 2003).

Predetermination of the location parameters of the PDFs or the CDFs used in studies involving diameter class models usually depends on the minimum diameter of the distributions (Zanakis 1979; Hawkins et al. 1988; Knoebel and Burkhart 1991; Zhang et al. 2003; Scolforo et al. 2003; Parresol 2003; Cao 2004, Liu et al. 2004, Fonseca et al. 2009; Gorgoso et al. 2012), and a suitable value of the location parameter is an important factor in the final accuracy of the models. In distributions including high minimum diameter values, a low value of the location parameter is probably not appropriate. Zanakis (1979) developed a method for estimating the location parameter of the Weibull distribution that takes into account the two smallest diameters and the maximum diameter in each plot. However, interpretation of the parameters of the CDF of minimum diameters described by the Gumbel and the Weibull functions can also help in selecting the most suitable value of the location parameter as a fraction of the minimum diameters observed. For example, Gorgoso et al. (2012) obtained the lowest values of the MSE with the Johnson's $S_{B}$ PDF fitted by the conditional maximum likelihood to the same pine data, considering $0.5 \cdot d_{\text {min }}$ in $P$. sylvestris L. stands (in which the minimum diameters are the lowest) and $0.75 \cdot d_{\min }$ in 
Table 4 Mean values of the bias, mean absolute error (MAE), mean square error (MSE) and Kolmogorov-Smirnov statistic $\left(D_{n}\right)$ in fitting the Gumbel and the Weibull functions to extreme diameter values $d_{\max }$ maximum diameters, $d_{\min }$ minimum diameters

\begin{tabular}{|c|c|c|c|c|c|c|}
\hline & & & Bias & MAE & MSE & $D_{n}$ \\
\hline \multirow[t]{10}{*}{ Gumbel (moments) } & \multirow[t]{2}{*}{ Quercus robur } & $d_{\max }$ & 0.00759 & 0.015875 & 0.000417 & 0.082850 \\
\hline & & $d_{\min }$ & 0.026027 & 0.032708 & 0.002466 & 0.117176 \\
\hline & \multirow[t]{2}{*}{ Betula pubescens } & $d_{\max }$ & 0.010553 & 0.020714 & 0.000632 & 0.086893 \\
\hline & & $d_{\min }$ & 0.051092 & 0.057707 & 0.010813 & 0.264262 \\
\hline & \multirow[t]{2}{*}{ Pinus pinaster } & $d_{\max }$ & 0.004600 & 0.025312 & 0.001021 & 0.085028 \\
\hline & & $d_{\min }$ & 0.027465 & 0.045789 & 0.004513 & 0.149053 \\
\hline & \multirow[t]{2}{*}{ Pinus radiata } & $d_{\max }$ & 0.003755 & 0.035125 & 0.002004 & 0.096984 \\
\hline & & $d_{\min }$ & 0.02882 & 0.038438 & 0.004797 & 0.193674 \\
\hline & \multirow[t]{2}{*}{ Pinus sylvestris } & $d_{\max }$ & 0.009353 & 0.019893 & 0.000545 & 0.085996 \\
\hline & & $d_{\min }$ & 0.037638 & 0.046373 & 0.005020 & 0.144624 \\
\hline \multirow[t]{10}{*}{ Gumbel (mode) } & \multirow[t]{2}{*}{ Quercus robur } & $d_{\max }$ & 0.144793 & 0.144793 & 0.033133 & 0.342510 \\
\hline & & $d_{\min }$ & -0.03901 & 0.039053 & 0.003984 & 0.162563 \\
\hline & \multirow[t]{2}{*}{ Betula pubescens } & $d_{\max }$ & 0.07288 & 0.07288 & 0.0076262 & 0.166587 \\
\hline & & $d_{\min }$ & 0.00244 & 0.029157 & 0.001992 & 0.106691 \\
\hline & \multirow[t]{2}{*}{ Pinus pinaster } & $d_{\max }$ & -0.13504 & 0.135990 & 0.027503 & 0.311098 \\
\hline & & $d_{\min }$ & -0.07460 & 0.075852 & 0.007770 & 0.123290 \\
\hline & \multirow[t]{2}{*}{ Pinus radiata } & $d_{\max }$ & -0.07020 & 0.073562 & 0.008171 & 0.175606 \\
\hline & & $d_{\min }$ & -0.00258 & 0.023599 & 0.000996 & 0.086977 \\
\hline & \multirow[t]{2}{*}{ Pinus sylvestris } & $d_{\max }$ & 0.162880 & 0.162880 & 0.042118 & 0.400027 \\
\hline & & $d_{\min }$ & -0.02198 & 0.022367 & 0.000745 & 0.201514 \\
\hline \multirow[t]{10}{*}{ Weibull (moments) } & \multirow[t]{2}{*}{ Quercus robur } & $d_{\max }$ & 0.008782 & 0.01668 & 0.000472 & 0.059959 \\
\hline & & $d_{\min }$ & 0.018686 & 0.020814 & 0.001354 & 0.128429 \\
\hline & \multirow[t]{2}{*}{ Betula pubescens } & $d_{\max }$ & 0.012870 & 0.014557 & 0.000333 & 0.046444 \\
\hline & & $d_{\min }$ & 0.03162 & 0.043742 & 0.006297 & 0.233147 \\
\hline & \multirow[t]{2}{*}{ Pinus pinaster } & $d_{\max }$ & 0.006314 & 0.013081 & 0.000330 & 0.057444 \\
\hline & & $d_{\min }$ & 0.013129 & 0.044671 & 0.004724 & 0.217387 \\
\hline & \multirow[t]{2}{*}{ Pinus radiata } & $d_{\max }$ & 0.005806 & 0.023949 & 0.001144 & 0.090486 \\
\hline & & $d_{\min }$ & 0.023444 & 0.028656 & 0.002814 & 0.151675 \\
\hline & \multirow[t]{2}{*}{ Pinus sylvestris } & $d_{\max }$ & 0.010630 & 0.013970 & 0.000340 & 0.053777 \\
\hline & & $d_{\min }$ & 0.022079 & 0.028020 & 0.002455 & 0.158449 \\
\hline
\end{tabular}

$P$. radiata D. Don and $P$. pinaster Ait. stands (in which the minimum diameters were higher) (see Table 2). In the same study, the authors present a simple algorithm to define the optimum value of the location parameter for the Weibull, Johnson's $S_{B}$ and beta distributions fitted to the same data of pine species; the two-parameter Weibull distribution also yielded the best results for the $P$. sylvestris stands under study. The present results for the Gumbel distribution show a lower value of scale parameter $(\beta)$ for $P$. sylvestris stands (2.1) than that for $P$. pinaster (3.5) and $P$. radiata (4.2) stands, in concordance with the variability in the minimum values of the distributions of extreme values (see Table 2), which may indicate that low values of this parameter benefit the twoparameter models of the PDFs or that is necessary to predetermine low values of the location parameters of the threeparameter and four-parameter models. Similar behaviour in the scale parameters of the Weibull PDF was also obtained for these species.
The Weibull CDF was generally the most accurate function for describing the maximum diameter distributions, and it could also be used for diameter class models. For example, four-parameter distributions, such as the beta PDF, require the upper limit of the distribution to be predetermined. This value is the maximum diameter of the distribution or the upper limit of the highest diameter class, with or without extensions (Zöhrer 1969, 1970; Loetsch et al. 1973). Extensive studies of stem diameter distributions revealed that frequencies in the right tail, computed with the beta distribution, are sometimes too low and close to the upper limit. This defect was greatly reduced by iterated enlargements of the upper limit. This is justifiable by statistical considerations insofar as an increase in sample size also increases the probability of obtaining a higher maximum diameter (Loetsch et al. 1973). However, the optimum extension of the upper limit may be more closely related to the trend in the frequency of trees in the highest diameter classes than the value of the maximum diameter of the 
Fig. 1 a-j Observed cumulative distributions and distributions fitted using the Gumbel and Weibull CDFs to describe extreme diameter values for five tree species in NW Spain
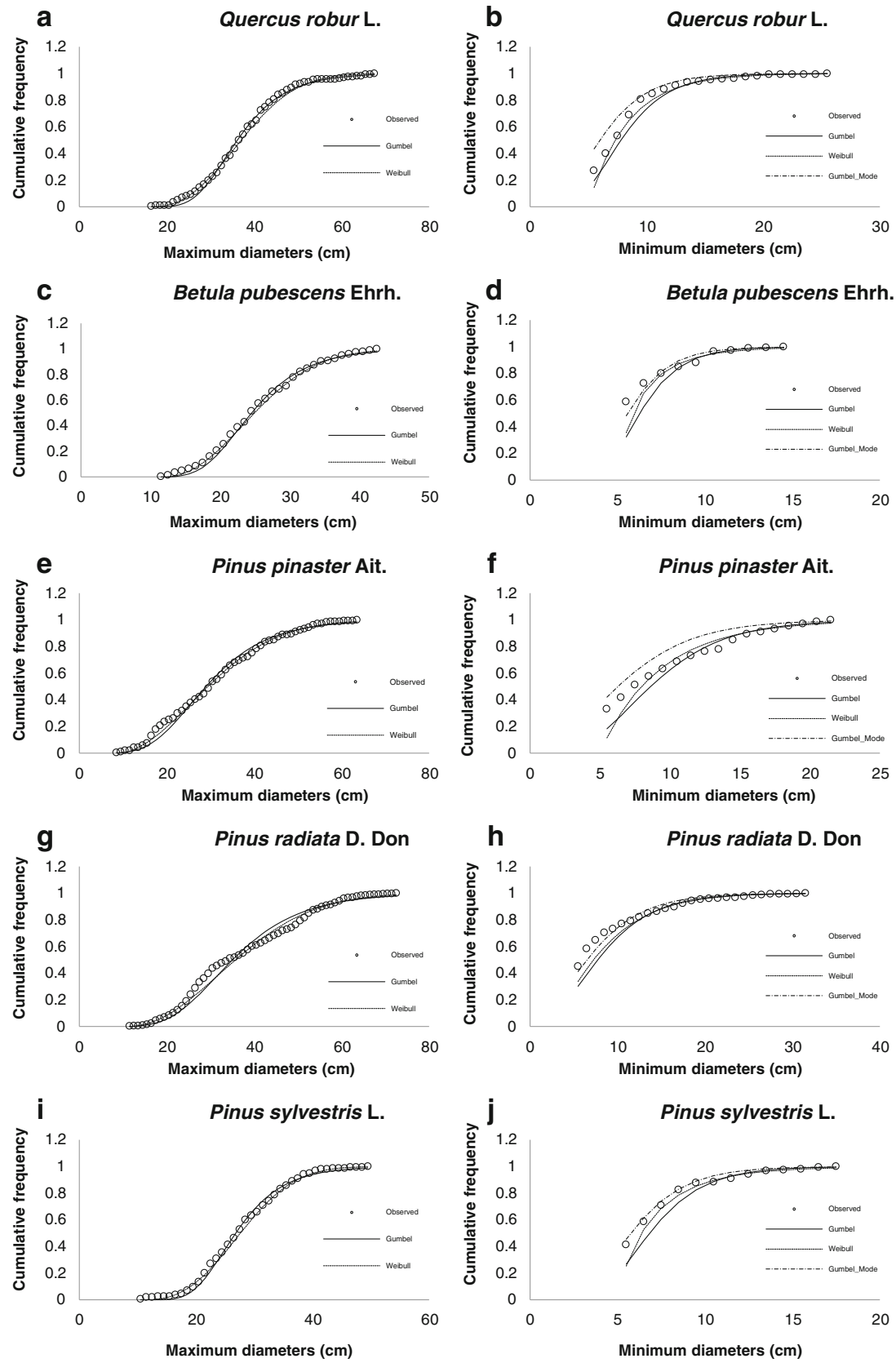

distribution. Maximum diameter has also been used to determine the scale parameter in the Johnson's $S_{B}$ PDF (Knoebel and Burkhart 1991; Gorgoso et al. 2012), and it has also been used to estimate the scale parameter as the range of the distributions (Schreuder and Hafley 1977; Scolforo et al. 2003).

Maximum diameters also are used in some generalized height-diameter models, sometimes as one of the independent variables (Lenhart 1968; Amateis et al. 1995). Such models yielded determination coefficients $\left(R^{2}\right)$ of 0.912 and 0.911 , respectively, for radiata pine in Galicia (LópezSánchez et al. 2003).
In summary, the method of estimating location parameters of the PDFs or CDFs involves extracting the minimum diameters from each distribution and fitting a theoretical extreme value distribution. The Gumbel and the Weibull CDFs are suitable for describing the distributions of minimum and maximum diameters, although the mode method of estimating the Gumbel is preferred for samples with low values of the smallest percentiles. This approach cannot be used for maximum diameters. The low values of the scale parameter of both distributions may indicate the suitability of low values of the location parameter of the distributions used in the diameter class models. 
Finally, maximum diameters are important for timber harvesting, because sawing and processing operations depend on the size of harvesting and felling heads of these machines. For some types of harvesting and felling heads, the maximum diameter for sawing and cutting is around $51 \mathrm{~cm}$, although more expensive machinery may enable processing of trees of maximum diameters up to $95 \mathrm{~cm}$.

In conclusion, the Gumbel distribution was used for the first time in the field of forest modelling to describe extreme values of maximum and minimum diameter distributions in forest stands in NW Spain. In some cases, the approach produced better results than with the Weibull distribution. The results are applicable to forest modelling and to some practical cases, such as modelling maximum diameters for sawing and processing purposes.

Acknowledgments The authors thank forestry students from the Universities of Oviedo and Santiago de Compostela who participated in the fieldwork.

Funding The study was financially supported by the Gobierno del Principado de Asturias through the following projects: 'Estudio del crecimiento y producción en pinares regulares de Pinus radiata D. Don. en Asturias (PC04-57)' and 'Estudio del crecimiento y producción de Pinus pinaster Ait. en Asturias (CN-07-094)'. The Unidade de Xestión Forestal Sostible (UXFS) Research Group is partly funded by the Galician regional government through the consolidation programme and Structuring Competitive Research Units 2011, co-financed by the European Regional Development Fund (ERDF).

\section{References}

Amateis R.L., Burkhart H.E. and Zhang S., 1995. TRULOB: tree register updating for loblolly pine (an individual tree growth and yield model for managed loblolly pine plantations). Coop. Rep. 83. Blacksburg, VA: Virginia Polytechnic Institute and State University, Department of Forestry, Loblolly Pine Growth and Yield Cooperative.

Bailey RL, Dell TR (1973) Quantifying diameter distributions with the Weibull function. For Sci 19:97-104

Burke EJ, Perry RHJ, Brown SJ (2010) An extreme value analysis of UK drought and projections of change in the future. J Hydrol 388:131143

Cao QV (2004) Predicting parameters of a Weibull function for modeling diameter distribution. For Sci 50:682-685

Fisher RA, Tippett LHC (1928) Limiting forms of the frequency distribution of the largest or smallest member of a sample. Proc Camb Philos Soc 24:190-190

Fonseca TF, Marques CP, Parresol BR (2009) Describing maritime pine diameter distributions with Johnson's $\mathrm{S}_{\mathrm{B}}$ distribution using a new all-parameter recovery approach. For Sci 55:367-373

Gerald CF, Wheatley PO (1989) Applied numerical analysis, 4th edn. Addison-Wesley, Reading

Gorgoso JJ, Rojo A, Cámara-Obregón A, Diéguez-Aranda U (2012) A comparison of estimation methods for fitting Weibull, Johnson's $\mathrm{S}_{\mathrm{B}}$ and beta functions to Pinus pinaster, Pinus radiata and Pinus sylvestris stands in northwest Spain. For Syst 21:446-459

Gorgoso-Varela JJ, Rojo-Alboreca A, Afif-Khouri E, Barrio-Anta M (2008) Modelling diameter distributions of birch (Betula alba L.) and pedunculate oak (Quercus robur L.) stands in northwest Spain with the beta distribution. Invest Agrar Sist Recur For 17:271-281

Gumbel E.J., 1954. Statistical theory of extreme values and some practical applications. Applied Mathematics Series, 33. U.S. Department of Commerce, National Bureau of Standards.

Hafley WL, Buford MA (1985) A bivariate model for growth and yield prediction. For Sci 31:237-247

Hawkins K, Hotvedt J, Cao Q, Jackson B (1988) Using the Weibull distribution to model harvesting machine productivity. For Prod J 38:59-65

Kangas A, Maltamo M (2000) Performance of percentile based diameter distribution prediction and Weibull method in independent data sets. Silva Fenn 34:381-398

Knoebel BR, Burkhart HE (1991) A bivariate distribution approach to modeling forest diameter distributions at two points in time. Biometrics 47:241-253

Lenhart J.D., 1968 Yield of old-field loblolly pine plantations in the Georgia Piedmont. M.S. thesis, Univ. of Georgia, Athens, GA.

Liu C, Zhang SY, Lei Y, Newton PF, Zhang L (2004) Evaluation of three methods for predicting diameter distributions of black spruce (Picea mariana) plantations in central Canada. Can J For Res 34:2424 2432

Loetsch F, Zöhrer F, Haller KE (1973) Forest inventory 2. Verlagsgesellschaft, BLV. Munich, $469 \mathrm{p}$

López-Sánchez CA, Gorgoso-Varela JJ, Castedo-Dorado F, RojoAlboreca A, Rodríguez-Soalleiro R, Álvarez-González JG, Sánchez-Rodríguez F (2003) A height-diameter model for Pinus radiata D. Don in Galicia (northwest Spain). Ann For Sci 60:237245

Maltamo M, Puumalainen J, Päivinen R (1995) Comparison of beta and Weibull functions for modelling basal area diameter distribution in stands of Pinus sylvestris and Picea abies. Scan J For Res 10:284295

MMAMRM (Ministerio de Medio Ambiente y Medio Rural y Marino). 2011. Cuarto Inventario Forestal Nacional. Galicia. 52 pp.

Nanang DM (1998) Suitability of the normal, log-normal and Weibull distributions for fitting diameter distributions of neem plantations in northern Ghana. For Ecol Manage 103:1-7

Parresol B.R., 2003. Recovering parameters of Johnson's $\mathrm{S}_{\mathrm{B}}$ distribution. Res. Pap. SRS-31. Asheville, NC: U.S. Department of Agriculture Forest Service, Southern Research Station. 9 p.

Persson K, Rydén J (2010) Exponentiated Gumbel distribution for estimation of return levels of significant wave height. J Environ Stat 1: $1-12$

Ritzema H.P. (Ed). 1994. Frequency and regression analysis. Chapter 6 in. Drainage principles and applications, 16:175-224. International Institute for Land Reclamation and Improvement (ILRI), Wageningen, The Netherlands.

SAS Institute INC. 2003. SAS/STAT ${ }^{\mathrm{TM}}$ user's guide, version 9.1. Cary, North Carolina.

Schreuder HT, Hafley WL (1977) A useful bivariate distribution for describing stand structure of tree heights and diameters. Biometrics 33:471-478

Scolforo JRS, Vitti FC, Grisi RL, Acerbi F, De Assis AL (2003) $\mathrm{S}_{\mathrm{B}}$ distribution's accuracy to represent the diameter distribution of Pinus taeda, through five fitting methods. For Ecol Manage 175:489-496

Shifley SR, Lentz EL (1985) Quick estimation of the three-parameter Weibull to describe tree size distributions. For Ecol Manage 13:195203

Stankova TV, Zlatanov TM (2010) Modeling diameter distribution of Austrian black pine (Pinus nigra Arn.) plantations: a comparison of the Weibull frequency distribution function and percentile-based projection methods. Eur J Forest Res 129:1169-1179

Willemse WJ, Kaas R (2007) Rational reconstruction of frailty-based mortality models by a generalisation of Gompertz' law of mortality. Insur Math Econ 40:468-484 
Zanakis SH (1979) A simulation study of some simple estimators for the three parameter Weibull distribution. J Stat Comput Simul 9:101-116

Zhang L, Packard KC, Liu C (2003) A comparison of estimation methods for fitting Weibull and Johnson's $S_{\mathrm{B}}$ distributions to mixed spruce-fir stands in northeastern North America. Can J For Res 33:1340-1347

Zhou B, McTague JP (1996) Comparison and evaluation of five methods of estimation of the Johnson system parameters. Can J For Res 26: 928-935
Zöhrer F (1969) The application of the beta function for best fit of stem diameter distributions in inventories of tropical forest. Mitt. Bundesforsch-.anst. Forst-u. Holzwirtsch. Reinbek Hambg 74: 279-293

Zöhrer F., 1970. Das Computerprogram BETKLA zum Ausgleich von Stammzahl-Durchmesserverteilungen mit Hilfe der Beta-Verteilung. Mitt. Bundesforsch-.anst. Forst- u. Holzwirtsch., Reinbek/Hamburg $76,50 \mathrm{p}$. 